\title{
The prevalence of positive LE cell and anti-DNA tests in a population of Thai adolescents
}

\author{
Suphan Soogarun ${ }^{1}$ and Viroj Wiwanitkit ${ }^{2}$ \\ ${ }^{1}$ Clinical Microscopy Research Unit, Department of Clinical Microscopy, Faculty of Allied Health Sciences, \\ Chulalongkorn University, Bangkok Thailand 10330. \\ ${ }^{2}$ Department of Laboratory Medicine, Faculty of Medicine, Chulalongkorn University, Bangkok Thailand 10330.
}

Accepted 7 August, 2007

\begin{abstract}
The incidence of Systemic Lupus Erythematosus (SLE) in Thailand is not well described. Here, we report the prevalence of a positive LE cell test and anti-dDNA latex agglutination test among a sample of Thai adolescents. Of 80 Thai young adolescent subjected to a positive LE cell test and anti-dDNA latex test was found one case having clinical presentations from mild to moderate symptoms, giving the prevalence equal of $1.25 \%$.
\end{abstract}

Key words: SLE, Thai adolescent, prevalence.

\section{INTRODUCTION}

The diagnosis of systemic lupus erythematosus (SLE) is made using clinical and laboratory criteria, including the results of immunological tests. Sometimes these immunological tests are difficult to perform and require sophisticated equipment which is not easily available in developing countries such as Thailand. Therefore, screening tests, such as LE preparation and the latex test are still necessary for the diagnosis of SLE.

The incidence of SLE in the tropics is not well described. Recently, Vilar and Sato (2002) demonstrated a high incidence of SLE in Brazil, apparently higher than reported in other places. The observed differences may be due to ethnic and/or environmental factors. In Thailand, Wananukul et al. (2005) recently reported the prevalence of positive antinuclear antibodies in healthy children. In this work, we found that the prevalence of positive ANA using the HEp-2 cells as substrate was 15\% in healthy children at dilutions of 1:40 or higher.

\section{MATERIALS AND METHODS}

This study was performed as a descriptive study. In a laboratory class of third year medical technologist students at the Faculty of

\footnotetext{
*Corresponding author. E-mail: supunsug@yahoo.com.
}

Allied Health Sciences Chulalongkorn University, the LE preparation test (standard method) and anti-dDNA latex agglutination test (direct method) were performed on all 80 medical technologist students using the routine methods. The results were analyzed to determine the prevalence of a positive test.

\section{RESULTS AND DISCUSSION}

Of the 80 medical technology students (age between 15 -20 years old), a positive LE cell test and anti-dDNA was found in only one case, giving a prevalence of $1.25 \%$. No participant had at least one positive test. The case with a positive result was female student and further investigations revealed she met the criteria for the diagnosis of SLE by the American Association of Rheumatology (1997) (skin rash, ANA positive, photosensitivity).

The prevalence of SLE in tropical countries such as Thailand is not well documented. There is no routine screening for SLE among healthy subjects in Thailand. ANA tests are sometimes used to diagnose children with chronic inflammatory diseases such as SLE (McGhee et al., 2004). However, the diagnostic utility of this test is limited because of the large number of healthy children who have low-titer positive tests (McGhee et al., 2004). It is expensive and not cost effective compared to LE preparation (Wiwanitkit, 2003). Therefore, LE preparation is suggested for resource limited settings such as Asia 
and Africa. A recent Thai questionnaire screening for SLE was proposed (Kasitanon et al., 2006), but it does not take into account laboratory evidence. According to our study, the prevalence of a positive LE cell test and latex test among our sample of Thai young adolescents is high. Our rate is similar to the rate of a positive ANA test in healthy Thai children (Wananukul et al., 2005). A comparison of LE cell and anti-DNA positivity of this population with other ethnic groups would be of interest. However, there are limited reports on the rate within normal population. Sigler et al. (1958) reported the rate as $24 \%$ in the rheumatoid arthritis in USA.

Some limitations in this study should be addressed. Although screening tests such as LE preparation and the latex test are still necessary for the diagnosis of SLE in developing countries since immunological tests are difficult to perform and require sophisticated equipment which is not easily available. However, the LE test is time consuming and requires a skilled technician to interpret the cytology. In addition, the LE cell test is not currently used for the diagnosis of SLE because its lack of specificity. In fact, the LE cell test was excluded as a criterion from the American College of Rheumatology revised criteria for the classification of systemic lupus erythematosus (Hochberg, 1997). The hemagglutination technique is the least specific of all methods employed for the detection of anti-DNA antibodies, being the Crithidia luciliae and Farr methods, the most specific and most commonly used. Since SLE patients may have negative LE cell and anti-DNA tests, all study participants should have been examined for the possibility of SLE and other autoimmune connective tissue disorders. Therefore, the methods in this study are not to directly determine the prevalence of SLE but positive LE cell and anti-DNA tests. This study only examines the prevalence of positive LE cell and anti-DNA tests in a population of Thai adolescents, not the prevalence of SLE. Prevalence studies are conducted in large populations using general practice diagnostic registries, outpatient clinical records, physicians' surveys, and healthcare insurance companies' database, among others.

\section{REFERENCES}

Hochberg MC (1997). Updating the American College of Rheumatology revised criteria for the classification of systemic lupus erythematosus [letter]. Arthritis Rheum. 40: 1725

Kasitanon N, Louthrenoo W, Wangkaew S, Sukitawut W, Wichainun R (2006). Validation of the Thai version of a screening questionnaire for detection of systemic lupus erythematosus. J. Med. Assoc. Thai. 89(4): 448-52.

McGhee JL, Kickingbird LM, Jarvis JN (2004). Clinical utility of antinuclear antibody tests in children. BMC Pediatr. 4: 13.

Sigler JW, Monto RW, Ensign DC, Wilson GM, Rebuck JW, Lovett JD (1958). The incidence of the L.E. cell phenomenon in patients with rheumatoid arthritis. (A two-year study). Arthritis Rheum. Apr; 1(2): 115-21.

Vilar MJ, Sato El (2002). Estimating the incidence of systemic lupus erythematosus in a tropical region (Natal, Brazil). Lupus. 11(8): 52832.

Wananukul S, Voramethkul W, Kaewopas Y, Hanvivatvong O (2005). Prevalence of positive antinuclear antibodies in healthy children. Asian Pac J Allergy Immunol. 23(2-3): 153-7.

Wiwanitkit V (2003). Is the SLE latex test more appropriate than the LE cell preparation in screening for SLE? Haema. 6: 512-514. 